\title{
THE STATUS AND FUTURE OF DIAMOND EXPLORATION IN CHINA
}

Zhang Andi; Xu Dehuan; Xie Xiling; Guo Lihe; Zhou Jianzong and Wang Wuyi. Institute of Mineral Deposits, Chinese Academy of Geological Sciences, Beijing 100037, China.

Diamond exploration in China is discussed, based on the statistical study of the chemistry of macrocryst garnets and chrome-spinels from concentrates of 68 bodies of both chinese and non-Chinese kimberlites, lamproites and lamprophyres, integrated with available chemical data for inclusions in diamonds from Chinese kimberlites, plus geological and tectonic information.

Diamonds occur in three major cratons of China, namely, Sinokorean, Yangtze and Tarim, but kimberlites are mainly found in the Sinokorean craton. Eight kimberlite fields have been recognized (Fig. 1). Only four are diamondiferous, i.e. Fuxian, Tieling and Huanren in Liaoning province and Mengyin in shandong province, and all these are all restricted to the vicinity of the Liaolu terrain (Wu Jiashan et al.1990). These kimberlite occurrences are mainly small dykes and small pipes. Only two are mined, i.e. pipe no. 50 in Fuxian and Shenglie no.1 in Mengyin, which are deeply eroded. In outcrop, either root zone hypabyssal facies or facies transitional between diatreme and root zone can be easily identified. Pipe no. 50 produces high quality gemstones at a grade of about 60-230 cts/100t, and has dimensions of $245 \times 55 \mathrm{~m}$, while the pipe of Shengli No. 1 yields a grade of $40-250 \mathrm{cts} / 100 \mathrm{t}$ and is $5000 \mathrm{~m}$ \# in size. As to size and grade of these two pipes, it is difficult to compare them with pipes in Yakutia like Mir or Udachnaya and in South Africa like Finsch or others, but the Sobolev garnet $\mathrm{CaO}-\mathrm{Cr}_{2} \mathrm{O}_{3}$ diagrams of the two Chinese kimberlite pipes and the chemistries of their diamond inclusions are quite similar to those from kimberlites of Vilui in Yakatia and the Kaapvaal craton of South Africa (Eig. $2 a-d)$. This shows that the constitutions of the upper mantle under the Sinokorean, Vilui and Kaapvaal cratons are the same, and characterized by four subparageneses of peridotites, i.e. harzburgite, dunite, lherzolite and wehrlite, with lherzolite always dominant as it is the major constituent of the upper mantle (Lucas et al.1989). In addition, the chemistry of subcalcic Cr-pyrope, Na-bearing pyrope-almandine and Cr-spinel from concentrates, together with diamond inclusions of chinese and non-Chinese kimberlites, are also similar. A tectonicmagmatic arc, represented by a granite-greenstone belt, is recognized, which separated the Sinokorean Craton into two parts. So far all the diamondiferous kimberlites and placers occur only in the eastern part (the Liaolu terrain) which extends from Baishanzhen (Jilin province), through Qinyuan and Anshan (Liaoning province) to Taishan (Shandong province). This terrain is considered to be the most prospective target area for diamonds of kimberlitic type in china.

Another four kimberlite fields have been found in the western part of the craton. From North to South (Fig. 1), Yinxian, Shexian and Hebi occur along Taihang fault zone while Liulin 
is located in Luliang mountain area. The kimberlites are well differentiated serpentine calcite types which contain relatively small amounts of olivine macrocrysts. The content of xenocrysts is low and they are invariable in composition, with pyrope low in $\mathrm{Cr}$; no G10 pyrope, high Cr-spinel or diamonds have been found. The basement beneath the Taihang fault strand is a Pt $1-2$ paleorift zone, thus explaining the occurrence of barren kimberlites in this area.

So far, lamproites have been found only in the Yangtze craton. This craton contains "Proton" basements situated in central Sichuan and on the western flange of the craton, both of them having $1850 \mathrm{Ma}$ as the age of cratonization. That in central Sichuan is overlain by a Mesozoic basin, but the vast area to the south of it, including southeastern Sichuan, northeastern Guizhou and western Hubei (the Wuling mountain area) is worthy of attention for diamonds. High-Cr spinels $\left(\mathrm{Cr}_{2} \mathrm{O}_{3} \approx 67 \%\right)$ have been recovered from stream concentrates and $>2.5 \mathrm{Ga}$ basement ages have been obtained. The similarity of $\mathrm{Cr}_{2} \mathrm{O}_{3}-\mathrm{Al}_{2} \mathrm{O}_{3}$ diagrams of lamproite Cr-spinels from the Yangtze and $W$. Australia Kimberley cratons suggests that the upper mantle is similar under these two areas. Logically therefore, Wuling mountain area is probably the most prospective area within the craton. Overall, the Yangtze craton is a prospective target area for diamonds of lamproitic type (Fig. 2e-h).

\section{References}

Lucas, H., Ramsay, R.R., Hall, A.E., Smith, C.B. and Sobolev, N.V.

(1989). Garnets from Western Australian kimberlites and related

rocks. In: Kimberlites and related rocks, 2, Geological Society of Australia, Special publication No. 14, 809-819.

Wu Jiashan, Geng Yuansheng, Tang Lianjiang and Zhang Andi (1990).

Relationship of diamondiferous kimberlites with tectonic setting of basement in Sino-Korean platform (in press).

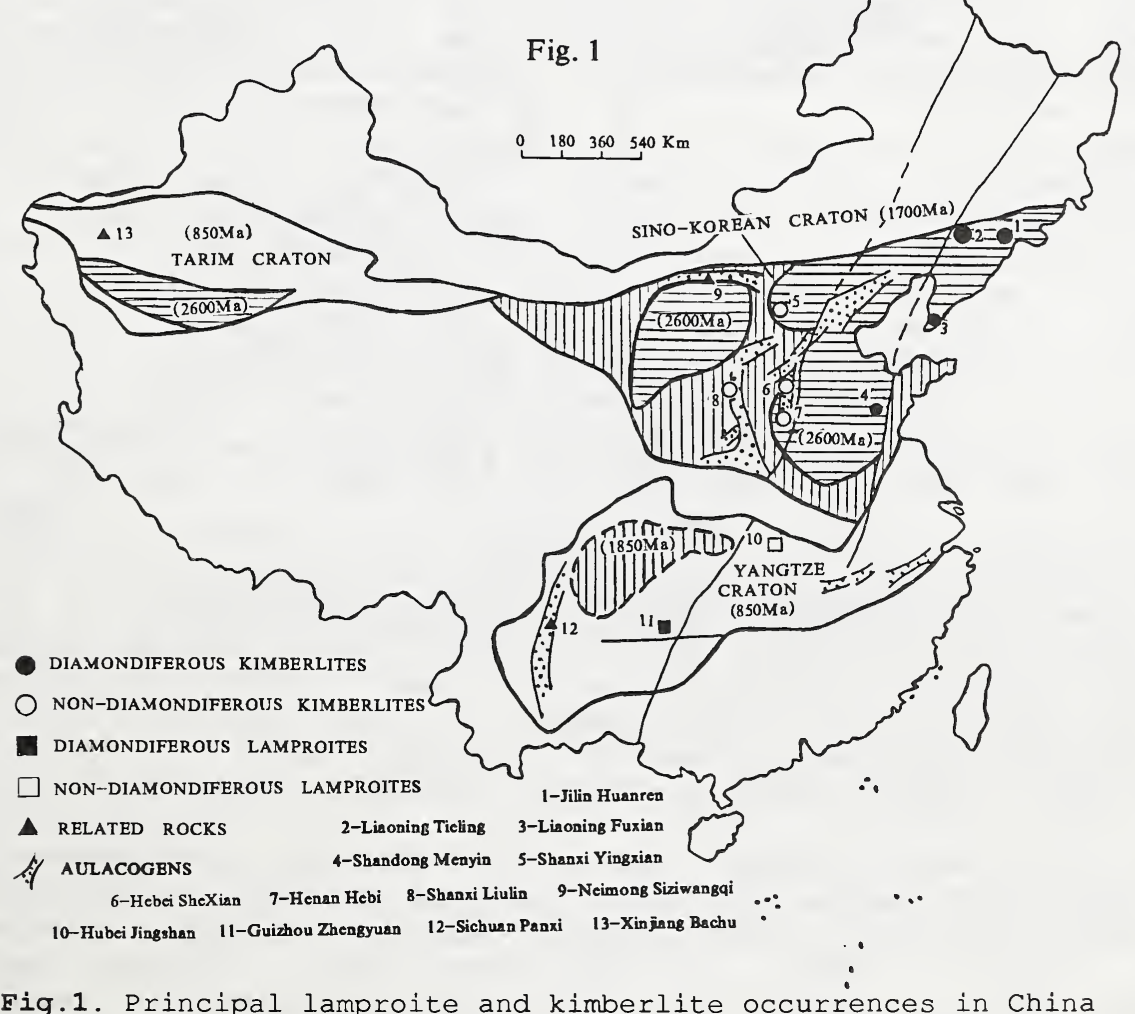

Fig.1. Principal lamproite and kimberlite occurrences in china 

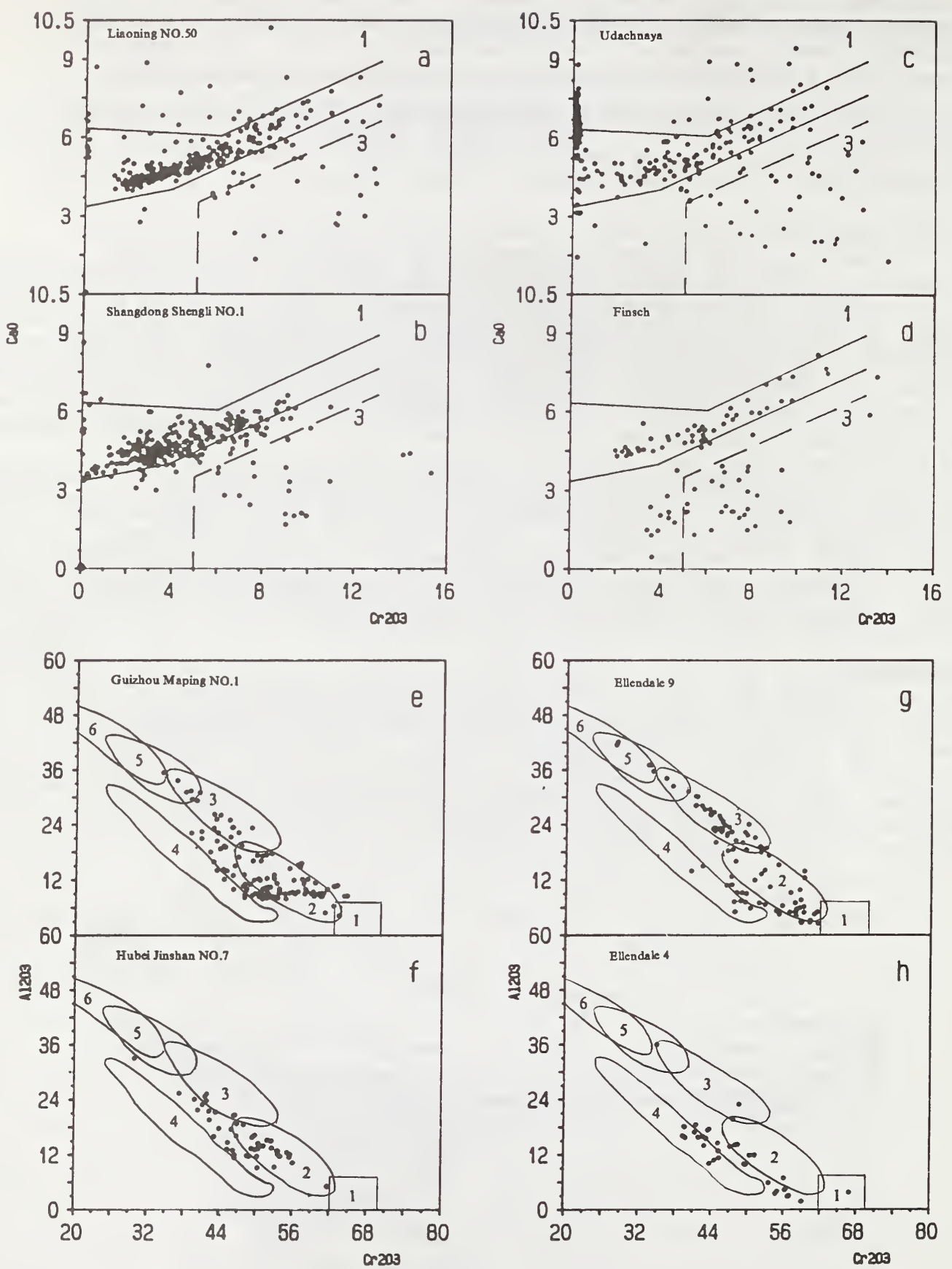

Fig. 2

e-h: 1-Diamond-Chromite facies; 2-Cocsite facies; 3-Grospydite facies; 4-Dunite facies; 5-Spincl-Pyrope facies; 6-Spincl-Pyroxen facies 